\title{
Effects of straw's comprehensive utilization-technology on agricultural carbon emission in Jiangsu Province
}

\author{
Xue Qin ${ }^{1, a}$, Jun Yan ${ }^{1, b^{*}}$, Zhu G.Y., \\ ${ }^{1}$ School of Economics and Finance, Jiangsu University, Zhenjiang, Jiangsu, China.
}

\begin{abstract}
Straw resources are abundant in Jiangsu province, the utilization and burning of straw is an important problem in agriculture carbon emission reduction. In order to analyze the effect of straw's comprehensive utilization technology on agricultural carbon emission, the STIRPAT model is introduced, which takes straw utilization technology as the core explanatory variable while other influencing factors as control variables, and the ridge regression is adopted to conduct an empirical analysis on the influencing factors of agricultural carbon emission in Jiangsu province from 2008 to 2018 . The results demonstrate that for every $1 \%$ increasing of straw's comprehensive utilization technology, agriculture carbon emission will be reduced by $0.17 \%$; the labor force is the biggest driver of agriculture carbon emissions; agriculture economic development, energy consumption takes a certain inhibitory effect on agriculture carbon emissions, but not very great.
\end{abstract}

\section{1 introduction}

As a large agricultural production country, a large amount of crop straw is produced every year in China. However, the comprehensive utilization rate of straw is not ideal, many straw resources are not fully utilized, but are burned or abandoned, which has a serious impact on the agricultural environment. In recent years, with the continuous introduction of straw burning prohibition and comprehensive utilization policies, the utilization efficiency of straw and the agricultural environment have been greatly improved.

In the study of the impact of straw comprehensive utilization technology on agricultural carbon emissions, we found that many scholars have conducted in-depth research on the impact of a certain straw treatment method on the agricultural environment [1-4]. Of course, there are also a lot of literature studied on the impact of straw burning on the air environment [5-7]. However, there are few studies on the effect of straw comprehensive utilization on agricultural carbon emissions. Johnson et al. found that agricultural material waste and crop combustion are important sources of agricultural carbon emissions by analyzing the main agricultural carbon sources [8]; Tasman found that different agricultural production methods lead to differences in agricultural carbon emissions between countries by comparing the differences in agricultural carbon emissions between countries [9]. Sun M.X. et al. evaluated the impact of different utilization methods of wheat straw on the environment through the life cycle assessment method, and the results showed that the new straw pulping had the best environmental protection, and the open burning type had the worst environmental protection [10].

Combing the existing literature provides a good reference for further research, but there are still some deficiencies in the existing research results. Firstly, most of the literature focuses on the single utilization of straw, while the research on comprehensive utilization of straw is still relatively weak. And then, in terms of research methods, most articles on straw use experimental method to conduct quantitative analysis on crop yield and other aspects, while there are few empirical analysis related to this. At the same time, previous studies have proposed that agricultural waste and burning are also important sources of carbon emissions. Therefore, it is reasonable for us to incorporate the comprehensive utilization technology of straw into the research on the impact of agricultural carbon emissions. Based on this, this paper uses STIRPAT model to study the driving factors of agricultural carbon emissions in Jiangsu Province from 2008 to 2018, and tries to explore the influence of various influencing factors on agricultural carbon emissions by adjusting the input structure of different projects in order to obtain better emission reduction effect. Hope some suggestions for policy-making can be provided.

\section{Materials and Methods}

Many studies believe that agricultural carbon emissions are mainly caused by the input of agricultural materials, including fertilizer, pesticide, agricultural film, agricultural diesel, agricultural planting area and agricultural irrigation, which are also adopted by most scholars to calculate agricultural carbon emission. However, some studies have shown that crop burning is also one of the important reasons for agricultural carbon 
emissions, so it is reasonable to be included in the calculation formula of agricultural carbon emission (see formula 1).

$$
E=\sum E_{i}=\sum T_{i} * \delta_{i}+E_{s}
$$

In this formula, $\mathrm{E}$ is the total amount of agricultural carbon emissions, $E_{i}$ is the emission of various carbon sources, including fertilizer, pesticide, agricultural film, agricultural diesel, agricultural planting area and agricultural irrigation. $T_{i}$ is the amount of carbon source, $\delta_{i}$ is the emission factor of carbon source (see Table 1). $E_{S}$ is the estimated amount of carbon emissions from straw incineration, and the specific estimation formula is $E_{S}=$ straw untreated capacity * incineration ratio * carbon emission factor * carbon content. Among them, straw untreated capacity $=$ total straw resources * (1comprehensive utilization rate of straw); And refers to the research results of Shi Z.L. and Wang S.X. in 2017, the incineration ratio in Huang-Huai-Hai district was $8.4 \%$, and in 2008, the incineration ratio in Jiangsu Province was $31.9 \%$. Considering that the incineration ratio will change with the policies, the incineration ratio of straw was estimated by combing the issuing strength of straw burning ban policy since 2008 [11]. Referring to Zhou L.M. 's introduction and actual implementation of straw burning prohibition policy, the incineration ratio is estimated according to the three stages (see table 2) [12]. As for carbon emission factor, only $\mathrm{CO}_{2}$ and $\mathrm{CO}$ were considered in the carbon release of straw incineration, and other forms of carbon release were not considered in this paper. ( $\mathrm{CO}$ emission factor $102.2 \mathrm{~g} / \mathrm{kg}$ and $\mathrm{CO}_{2}$ emission factor $1390.4 \mathrm{~g} / \mathrm{kg}$ ) $[13,14]$. The data mentioned above are all from the China Environmental Statistical Yearbook and the China Statistical Yearbook.

Table 1 carbon source and carbon emission coefficient of agricultural carbon emission

\begin{tabular}{|c|c|c|}
\hline Carbon source & coefficient & reference \\
\hline chemical fertilizer & $0.8956 \mathrm{~kg} / \mathrm{kg}$ & West TO, Oak Ridge National Laboratory \\
\hline pesticides & $4.9341 \mathrm{~kg} / \mathrm{kg}$ & Oak Ridge National Laboratory \\
\hline agricultural film & $5.18 \mathrm{~kg} / \mathrm{kg}$ & $\begin{array}{l}\text { Institute of agricultural resources and ecological } \\
\text { environment, Nanjing Agricultural University }\end{array}$ \\
\hline agricultural diesel & $0.5927 \mathrm{~kg} / \mathrm{kg}$ & $\begin{array}{l}\text { IPCC United Nations Intergovernmental Panel of experts } \\
\text { on climate change }\end{array}$ \\
\hline Agricultural ploughing & $312.6 \mathrm{~kg} / \mathrm{km}^{2}$ & $\begin{array}{c}\text { College of biology and technology, China Agricultural } \\
\text { University }\end{array}$ \\
\hline agricultural irrigation & $266.48 \mathrm{~kg} / \mathrm{hm}^{2}$ & Duan, H.P. et al \\
\hline
\end{tabular}

Table 2 the incineration ratio of straw in different stages

\begin{tabular}{ccc}
\hline stage & period & the incineration ratio \\
\hline first stage $(\sim 2009)$ & Policy blank period & $31.9 \%$ \\
second stage $(2009 \sim 2012)$ & Policy embryonic stage & $20.15 \%$ \\
Third stage $($ since 2012) & Policy improvement period & $8.4 \%$ \\
\hline
\end{tabular}

The explanatory variable is straw's comprehensive utilization technology (SUT) which is usually measured by straw's comprehensive utilization rate. Generally, the improvement of straw comprehensive utilization technology will reduce the use of chemical fertilizer so as to reduce agricultural carbon emissions on the one hand, and improve the utilization efficiency of straw resources and low carbonization on the other hand. Therefore, it is expected that straw comprehensive utilization technology will have a certain inhibitory effect on carbon emissions.

Furthermore, there are many factors influencing the activities related to agricultural carbon emission. This paper selects some important factors as control variables, including Labor force(L), economic development level (EDL) and agricultural energy consumption (AEC). The specific processing as follows: $\mathrm{L}$ is measured by rural population; EDL is measured by GDP per capita in agriculture; AEC is measured by the proportion of the output value of the tertiary industry to the secondary industry. At the same time, the comprehensive utilization rate of straw comes from the annual announcement issued by Jiangsu Provincial Bureau of statistics and agricultural and rural Bureau, in which the data vacancy in 2010, 2011 and 2016 is filled by interpolation method; other data are from China Statistical Yearbook and Jiangsu statistical yearbook.

Based on the data obtained from the above processing, this paper used the STIRPAT model of nonlinear stochastic regression improved by Dietz et al. This model can not only solve the limitation of IPAT model that the change of a single variable cannot fix other variables, but also overcome the defect of proportional change of various influencing factors, which is more conducive to empirical analysis. Many scholars have modified and extended this model to meet the needs of different research purposes. This paper also extended STIRPAT model to 
study the impact of straw comprehensive utilization technology on agricultural carbon emissions in Jiangsu Province. Based on this, the following model can be established according to the actual situation of this paper.

$$
\begin{gathered}
\operatorname{LnACE}=c+\beta_{1} \operatorname{LnSUT}+\beta_{2} \operatorname{LnL}+\beta_{3} \operatorname{LnEDL+} \\
\beta_{4} \operatorname{LnAEC}+\varepsilon
\end{gathered}
$$

In the formula, ACE is the agricultural carbon emission, SUT is the straw's comprehensive utilization technology, L, EDL, AEC are a set of control variables, $\beta$ is the corresponding coefficient vector, and $\varepsilon$ is a residual term. The model is based on the logarithm of the original STIRPAT model, which can eliminate heteroscedasticity.

\section{Results \& Discussion}

According to previous studies, there may be serious multicollinearity problems among variables in STIRPAT model. In order to avoid this situation, we choose ridge regression, rather than OLS, for correlation analysis, which is a more practical and reliable regression method by abandoning the unbiased of least square method and obtaining regression coefficient at the cost of losing part of information and reducing precision. In this method, a nonnegative factor $\mathrm{K}$ is added to the main diagonal element of the independent variable standardization matrix to improve the stability of the estimation results. Therefore, we use the ridge regression to fit the abovementioned extended STIRPAT model in SPSS 25.0 software. By observing the ridge trace of coefficient values under different $\mathrm{K}$ values, we find that when $\mathrm{k}=0.6$, the model becomes stable and infinitely parallel to the $\mathrm{x}$ axis. At this time, the specific results of ridge regression are shown in Table 3.

Table 3. Estimation results of ridge regression

\begin{tabular}{ccccc}
\hline variable & $\boldsymbol{B}$ & $\boldsymbol{S E}(\boldsymbol{B})$ & $\boldsymbol{B e t a}$ & $\boldsymbol{B} / \boldsymbol{S E}(\boldsymbol{B})$ \\
\hline Ln SUT & -.1733 & .0230 & -.2658 & -7.5135 \\
Ln $P$ & 1.3747 & .3478 & .1693 & 3.9524 \\
Ln EDL & -.0894 & .01107 & -.2540 & -8.0712 \\
Ln AEC & -.0916 & .0251 & -.1738 & -3.6523 \\
Constant & -1.9304 & .3368 & .0000 & -5.7316 \\
R Square & .9402 & & & \\
F value & 23.6212 & & & \\
Sig F & .0008 & & & \\
\hline
\end{tabular}

According to the empirical results reported in Table 3, The R square of the model is 0.9402 , and the overall fitting effect of the model is good at the significant level of $5 \%$, there is a significant curve relationship between dependent variables and independent variables. Specifically, in the case of controlling variables, every $1 \%$ increase in straw comprehensive utilization rate will reduce agricultural carbon emissions by $0.17 \%$. It can be seen that straw comprehensive utilization technology has inhibitory effect on agricultural carbon emissions, but the effect is not significant. The possible reasons are as follows: (1) straw comprehensive utilization technology is only one aspect of agricultural technology innovation, not comprehensive. (2) Taking the comprehensive utilization rate of straw as the standard to measure the comprehensive utilization technology of straw will bring some traditional utilization ways that have nothing to do with straw technology innovation into it, which will make the index of comprehensive utilization technology of straw have a certain error with the actual value. What's more, when observing the influence of other control variables on agricultural carbon emissions, it is found that except for the positive relationship between the number of rural labor and carbon emissions, the level of economic development and energy consumption will inhibit carbon emissions. And the coefficients of the two are relatively small, which shows that although Jiangsu Province's carbon emission has got rid of the positive correlation with economic development, it has little inhibitory effect on carbon emission and technological innovation needs to be further strengthened.

\section{Conclusions}

The results show that, as the core explanatory variable, straw comprehensive utilization technology does inhibit agricultural carbon emissions; except for the number of labors, agricultural economic development and energy consumption will inhibit agricultural carbon emissions. From the elasticity coefficient of ridge regression estimation, the number of labor force is the most important factor affecting agricultural carbon emissions in Jiangsu Province, followed by straw comprehensive utilization technology; agricultural economic development and energy consumption have little impact on agricultural carbon emissions.

\section{Acknowledgments}

National Natural Science Foundation of China: Research on evolution mechanism and optimization of rural governance system under the dual change of "system culture" (Project No.: 71973054).

Project supported by Jiangsu University: the impact of straw comprehensive utilization technology on agricultural carbon emissions (project number: 19c063). 


\section{References}

1. Wang, N., Yan H.K., et al. Effects of different amount of straw returning on growth and yield of maize $[\mathrm{J}]$. Maize science, 2007, 15 (5): 100-103.

2. Wu, S.X., et al. Study on evaluation index system of emission reduction of straw feed technology [J]. Heilongjiang Animal Husbandry and veterinary, 2020, (04): 1-6.

3. Zhu, H., Hu, Q.C., et al. Progress in the development of fuel utilization of crop straw resources in China $[\mathrm{J}]$. China biogas, 2017, (02): 115-120.

4. Wu, G.Q., Current situation and Prospect of crop straw energy utilization industry in China [J]. Biotechnology industry, 2015, 2:7-14.

5. Li, Y., et al. Correlation analysis between air quality and straw burning: a case study of Harbin [J]. Surveying and spatial geographic information, 2020 (06): 98-100.

6. Zhong, F.Q., et al. Simulation analysis of the impact of straw burning on regional urban air quality [J]. Climate and environment research, 2017 (02): 149161.

7. Ren, J.Q., Yu, P.X., Xu, X.H. Straw Utilization in China-Status and Recommendations [J]. SUSTAINABILITY. 2019,11(6)

8. Johnson, J.M.F., Franzluebbers A.J., Weyers S.L. Agricultural opportunities to mitigate greenhouse gas emissions. Environmental Pollution, 2007, 150(1):107- 124.

9. ACIL Tasman Pty Ltd. Agriculture and GHG Mitigation Policy: Options in Addition to the CPRS. New South Wales: Industry \& Investment NSW,2009.

10. Sun, M.X, Xu, X.B. Environmental burdens of the comprehensive utilization of straw: Wheat straw utilization from a life-cycle perspective [J]. JOURNAL OF CLEANER PRODUCTION, 2020, 259.

11. Wang, S.X. Spatiotemporal distribution of air pollutant emissions from straw burning in China $[\mathrm{J}]$. China Science and technology paper online, 2008,3 (5): 329-333

12. Zhou, L.M. Implementation status and optimization of straw burning ban policy in Jiangsu Province [J]. Environmental health engineering, 2017, 25 (6): 1012

13. Zhao, J.N. Zhang, G.L. et al. Estimation of carbon emission from grain crop straw incineration in China [J]. Journal of agricultural environmental science, 2011,30 (4): 812-816.

14. Shi, Z.L, Jia, T. et al. Current situation of comprehensive utilization of crop straw and estimation of carbon emission from incineration in China [J]. Agricultural resources and Regionalization in China, 2017,38 (9): 32-37 